\title{
Belvederes of philosophy and knowledge
}

Dr Michael Fascia

Visiting Professor, Campion Hall, University of Oxford

\section{ABSTRACT}

In this discussion, we consider the unity of knowledge, and deliberate a contrary perspective from current knowledge transfer practitioners, in a business context. We consider why, if knowledge is key for business success and competitive advantage, the transfer of knowledge remains for the most part a problematic event. Further, if the creation of knowledge before transfer is recognised within literature as a significant factor in determining a starting point for analogous scrutiny, then why is this focal point difficult to establish and measure.

Key words: Knowledge , Philosophy, Learning, Knowledge transfer

Paper type: Discussion 
This discussion will focus on the role of knowledge within known knowledge transfer arena's, in both academic and business communities. The debate highlights the importance in understanding of epistemic principles, evident in current theoretical interpretation surrounding knowledge in a knowledge transfer scenario. This underpinning is important, since philosophical interpretation of knowledge, for an organisation wishing to achieve a competitive advantage, may be achieved by aligning philosophical positioning to the cultural positioning of the firm or business (Michaelson, Pratt, Grant, \& Dunn, 2014).

Clearly, only by analysing the complete and somewhat complex knowledge interpretation process, the identification of any 'successful' interaction between practitioners during knowledge transfer can be identified. Hence, it is clear why most current management literature focuses on considerations, which can be effectual in using this knowledge understanding to maintain competitive advantage.

Current authors such as (Shukla, 2015) and (Evangelista \& Durst, 2015) lament that a generally accepted working definition of knowledge for the organisational environment are yet to be established. Other authors advise that in addition to no agreed upon definition of knowledge within management literature, little in the way of commonality can be offered regarding consequent theoretical positioning (Rotaru, Churilov, \& Flitman, 2014). Additionally, (Donate \& Guadamillas, 2015) suggest that problems with knowledge transfer remain prevalent, since in the main, knowledge is difficult to define, can be ambiguous, unspecific and a dynamic phenomenon. further stress that because knowledge is a subjective perspective of an individual's experience, associated problems are inextricably related to the context of the knowledge itself.

Authors such as (Barnett, Vasileiou, Djemil,
Brooks, \& Young, 2011) indicate that an individuals past experiences related to knowledge can contribute to retaining this knowledge that personal resources may also contribute to this state.

Context from (Ahmad \& Daghfous, 2010; Clark et al., 1997; García-Fernández, 2015; Halilem, Bertrand, Cloutier, Landry, \& Amara, 2012) asserts this perspective very clearly by explaining that in this information age, even though knowledge cannot readily be identified on any balance sheet, it is identified as the singularly most valuable asset for a business or organisation. Therefore, the interpretive praxis for knowledge schema could be debated at length as there is no such thing as 'normal knowledge'.

However, for this discussion and in the spirit of understanding knowledge and philosophy, we can examine where knowledge is philosophically positioned in relation to a business context. It is also equally important to understand the significance of experiential reasoning behind this interpretive position of knowledge before it is transferred. Important because, the adaptation by the knowledge transfer practitioners involved purport to a position of justification in the transfer schema. Thus, examination of an overriding epistemic principal is required as a baseline for further critique.

Knowledge taxonomy, as discussed by (Basaruddin \& Haron, 2011; Bentahar, Moulin, \& Bélanger, 2010; Blackman \& Henderson, 2005; Bolisani \& Scarso, 2015) explain the types of knowledge related to business along with the necessary understanding of communication to transfer any notion of knowledge. Scrutiny of knowledge efficacy at this point often reflects egoistic conceptions of reality from a knowledge transfer practitioners perception or cautious belief of any experience other than that relative to the knowledge transfer scenario (Adams, Tranfield, \& Denyer, 2011; Baporikar, 2016; de Silva Garza \& Gero, 2009; Halilem et al., 2012). This is because knowledge transfer practitioners experiential 
accounts of knowledge would be unable to explain the putative distinctive value of knowledge. Since the practitioners view of knowledge is subjective, any possibly relevant mental states are experiential. As such, Knowledge from this perspective, can only exist because someone knows it in his mind, it is not an independent entity to be transferred, such as any material object might be.

In an attempt to reconcile these anomalies studies (Szulanski, 2000, 2001, 2002) defines knowledge as a 'causally ambiguous set of routines'. However, one could ask if the existence of knowledge, that in itself depends on the interpretation of a foundational normality is true, then all knowledge must derive from a consequence of foundational ethics which in themselves cannot be refuted by accepted moral norms. This situation is a perplexing situation to say the least. Thus. It might be said that our knowledge of that real world is fallible and theory laden. Wherein, it exists, but our knowledge of it is unclear, is singular in its focus and suffers from borrowed interpretations covering many disciplines.

In this sense, cognitive interpretations of knowledge vary, are often very broad or very nonspecific. For example it is clear that a distinction can often made between data, information and knowledge. Conversely, however, Knowledge could be described as an elusive concept or a multifaceted concept with multi-layered meanings. Nonetheless, because of the philosophical diversity surrounding the theoretical base of knowledge definition, research conclusions form many inconsistencies and variations. Yet, regardless of this indifference, there still exists agreement within many research streams that knowledge in a dissected form can be useful.

\section{PHILOSOPHICAL ARGUMENT}

From a philosophical position in Occidental society, the understanding of knowledge can generally be regarded as falling between two arguments, the first is Rationalism (Cummiskey, 2011; de Vazquez, 2015; Stephens, 1994; Stove, 1982) , (See Descartes, Leibniz, Kant) which postulates that a proposition can be known from reason alone without the need for, or indeed independent from, experience. The second is Positivism (de Vazquez, 2015; Demiray, 2016; Galavotti, 2015; Gargiulo, 2016) (see Aristotle, Berkeley, Kant), which postulates that propositions can only be known directly from experience.

Furthermore, in the context of this discussion, it is also important to recognise the impressions of Spinoza (See A Theological-Political Treatise 1670) since complimenting the rationalist connection, Spinoza contended that "God" and "Nature" were the same reality, namely a singularity that underlies the universe and everything else was simply modes or modifications. He contended that "Deus sive Natura" ("God or Nature") was of infinite attributes, hence, his account of reality was to understand physical and mental worlds as two different, parallel "subworlds", which neither overlap nor interact.

As a precursor to many theoretical positions based on philosophical precedence, we can therefore identify four succinct knowledge dimensions (Fascia, 2016; Jalloh, 1988; Lynch, 2004) which would enhance this capability to position knowledge relative to a personal interpretation. That is; tacit vs non tacit; observable vs non observable; simple vs non simple; and process dependent vs non process independent. Thus, knowledge may be classed as multi-faceted and is therefore easier to position in terms of value if it is first categorised into different asymmetries, which deliberately assume human beings hold beliefs in two distinct ways. Basic and non-basic. Hence, non-basic beliefs are based on other beliefs by interference, for example 'I believe that all green apples are sweet', is based on my inference that 'all apples are sweet'. Basic beliefs, are of course not, 
for example 'I believe that I am sitting in front of this computer, writing this discussion', is based on my experience I am having right now, not by inference of some other belief. Clearly, there is a fundamental problem in aligning these posits, regarding their usefulness in proposing underpinning knowledge values or even corrective knowledge transfer axioms. Since, both positional inferences, presuppose an assumption regarding cognitive psychology, in that, they both require interpretive associations regarding knowledge. Hence, from an easement of useful knowledge, they inextricably link knowledge and knowledge transfer as a worthwhile cognitive process.

\section{KNOWLEDGE POSITIONING}

This perspective indicates that at its core, the discussion of knowledge is concerned with the process of moving useful knowledge from one place to another for some benefit. A problem, from a philosophical perspective however confuses this issue, in that, if it is difficult to define the experiential primitives, such as personal experience, then it will be equally difficult to define the primitive concepts of knowledge. Thus, the question of why knowledge is more valuable than mere true belief, is really why issue of why knowledge is more valuable than any proper subset of its parts.

That is, does an actor specifically desire knowledge rather than epistemic standing, whereby, the importance of distinction between the two value problems is seen by considering that in some cases justification adds value to a mere true belief not to the knowledge. If this last point is right, then one might reasonably argue that the fact that knowledge entails justification since there would now be a property of knowledge which mere true belief lacks and which affords greater value to knowledge over mere true belief. One could argue however, if an actor in this position would thereby have an understanding of justified true belief, then the account of the value of knowledge ended at this point. Thus the epistemic value is of a justified true belief and not of the knowledge nor the sum of its parts.

Undoubtedly, this adds to the misunderstanding regarding any knowledge definition and any subsequent analysis or research therein. It is therefore surprising that such anomalies are considered almost redundant when enthusiastic interpretations of knowledge in a business context. In this sense, the fundamental assumption that, if given the correct circumstances and understanding, knowledge and its value can be created and universally transferred, unproblematically.

Similarly, its ultimate efficiency, underlining communication as an all incumbent sub set of functions. Thus, suggesting the characteristics of knowledge acquired by one actor, affect knowledge creation in another one. Although ultimately confusing, this view determines that the extended route of knowledge in a transfer scenario, knowledge is not regarded as an invariable or singular concept.

Though ultimately significant, it is the transfer parameters, which adopt the focus of prioritised importance and not the definition of the knowledge being transferred. This position of knowledge understanding and communication is therefore derived from a sequence of parameters, which are classified from a philosophical position of justifiable truth and belief. Thus, if this philosophical perspective reflects the locus of knowledge understanding, then one can conclude that the philosophical perspective of the knowledge to be transferred will also be derived from these unclear epistemological milieus.

\section{CONCLUSION}

This discussion has focused on outlining and assessment of current and historical knowledge philosophy, theory and positioning, but at the same 
time, places it within the realms of a business context. It concentrated on the epistemic principal of knowledge. The literature in this section indicated that the epistemic principal of knowledge is important as at its core the discussion of knowledge transfer is concerned with the process of moving useful knowledge from one place to another. However the literature concludes that at present there is no consolidated definition of knowledge in a business context .... or any other for that matter

\section{REFERENCES}

Adams, R., Tranfield, D., \& Denyer, D. (2011). A taxonomy of innovation: Configurations of attributes in healthcare innovations. International Journal of Innovation Management, $\quad$ 15(2), 359-392. doi: $10.1142 / \mathrm{S} 1363919611003192$

Ahmad, N., \& Daghfous, A. (2010). Knowledge sharing through inter-organizational knowledge networks. European Business Review, 22(2), 153-174. doi: http://dx.doi.org/10.1108/09555341011023506

Baporikar, N. (2016). Knowledge transfer issues in teaching: Learning management Innovation and shifting perspectives in management education (pp. 58-76): IGI Global.

Barnett, J., Vasileiou, K., Djemil, F., Brooks, L., \& Young, T. (2011). Understanding innovators' experiences of barriers and facilitators in implementation and diffusion of healthcare service innovations: A qualitative study. BMC Health Services Research, 11, 342. doi: http://dx.doi.org/10.1186/1472-6963-11-342

Basaruddin, S., \& Haron, H. (2011). Knowledge taxonomy for developing organizational memory system (oms) for public institutions of higher learning (ihl) in malaysia. In J. M. Zain, W. M. B. Mohd \& E. ElQawasmeh (Eds.), Software engineering and computer systems, pt 2 (Vol. 180, pp. 4357).

Bentahar, J., Moulin, B., \& Bélanger, M. (2010). A taxonomy of argumentation models used for knowledge representation. The Artificial Intelligence Review, 33(3), 211-259. doi: http://dx.doi.org/10.1007/s10462-010-9154-1

Blackman, D.A., \& Henderson, S. (2005). Know ways in knowledge management. The Learning Organization, 12(2), 152-168.

Bolisani, E., \& Scarso, E. (2015). Strategic planning approaches to knowledge management: A taxonomy. VINE, 45(4), 495-508.

Clark, J.M., Cordero, F., Cottrill, J., Czarnocha, B., DeVries, D.J., St. John, D., . . Vidakovic, D. (1997). Constructing a schema: The case of the chain rule? Journal of Mathematical Behavior, 16(4), 345-364.
Cummiskey, D. (2011). Korsgaard's rejection of consequentialism. Metaphilosophy, 42(4), 360-367. doi: 10.1111/j.1467-9973.2011.01696.x

de Silva Garza, A.G., \& Gero, J.S. (2009). Exploring knowledge transfer in a society of designers.

de Vazquez, M.T.G. (2015). The positiive notion of science of paul karl feyerabend. Critica-Revista Hispanoamericana De Filosofia, 47(141), 61-94.

Demiray, M.R. (2016). The intrinsic normativity of law in light of kant's doctrine of right. Con-Textos KantianosInternational Journal of Philosophy(3), 161-187. doi: 10.5281/zenodo.55112

Donate, M.J., \& Guadamillas, F. (2015). An empirical study on the relationships between knowledge management, knowledge-oriented human resource practices and innovation. Knowledge Management Research \& Practice, 13(2), 134-148. doi: http://dx.doi.org/10.1057/kmrp.2013.36 Evangelista, P., \& Durst, S. (2015). Knowledge management in environmental sustainability practices of third-party logistics service providers. VINE, 45(4), 509-529.

Fascia, M. (2016). Figurational dynamics: Attributes within a knowledge transfer scenario. THE JOURNAL OF STRATEGY, OPERATIONS \& ECONOMICS, 2(1), 1-10.

Galavotti, M.C. (2015). From the philosophy of science to the philosophy of the sciences. Journal of Philosophical Research, 45-54. doi: 10.5840/jpr201540Supplement8 García-Fernández, M. (2015). How to measure knowledge management: Dimensions and model. VINE, 45(1), 107. Gargiulo, T. (2016). Paul karl feyerabend's relativism. Ideas $Y \quad$ Valores, 65(160), 95-120. doi: 10.15446/ideasyvalores.v65n160.42248

Halilem, N., Bertrand, C., Cloutier, J.S., Landry, R., \& Amara, N. (2012). The knowledge value chain as an sme innovation policy instrument framework: An analytical exploration of smes public innovation support in oecd countries. International Journal of Technology Management, 58(3-4), 236-260. doi: 10.1504/IJTM.2012.046617

Jalloh, C.M. (1988). Fichte's kant-interpretation and the doctrine of science. Washington, D.C

Lanham, Md: Center for Advanced Research in Phenomenology ;

University Press of America.

Lynch, J. (2004). Comment section: Foucault on targets. Journal of Health Organization and Management, 18(2/3), 128-135.

Michaelson, C., Pratt, M.G., Grant, A.M., \& Dunn, C.P. (2014). Meaningful work: Connecting business ethics and organization studies. Journal of Business Ethics, 121(1), 7790.

Rotaru, K., Churilov, L., \& Flitman, A. (2014). Can critical realism enable a journey from description to understanding in operations and supply chain management? Supply Chain Management, $\quad 19(2), \quad 117-125 . \quad$ doi: http://dx.doi.org/10.1108/SCM-11-2013-0417

Shukla, M. (2015). An introduction to knowledge utilization capability and its autopoietic epistemological domain. 
Journal of the Knowledge Economy, 6(4), 1001-1012. doi: http://dx.doi.org/10.1007/s13132-013-0171-6

Stephens, W.O. (1994). Stoic naturalism, rationalism, and ecology. Environmental Ethics, 16(3), 275-286.

Stove, D.C. (1982). Popper and after : Four modern irrationalists. Oxford: Pergamon.

Szulanski, G. (2000). The process of knowledge transfer: A diachronic analysis of stickiness. Organizational Behavior and Human Decision Processes, 82(1), 9-27. doi: 10.1006/obhd.2000.2884

Szulanski, G. (2001). Knowledge creation: A source of value. Academy of Management. The Academy of Management Review, 26(2), 318-320.

Szulanski, G. (2002). Sticky knowledge : Barriers to knowing in the firm SAGE Strategy series (pp. 1 online resource (140 pages)). 